\title{
More on the Outbreak of Invasive Aspergillosis Among Allogeneic Bone Marrow Transplants at Roswell Park Memorial Institute
}

\section{To the Editor:}

The editorial by Rhame, commenting on the paper by Rotstein, et al (Infection Control, Vol. 6, No. 9, 1985) stated that "It is hard to escape concern that a scientific submission was modified to reduce the impact of pending litigation." Rhame is right to raise such concerns.

Our transplant unit was open for less than a year. The first few cases of Aspergillosis made us wary, but did not raise alarms, because we had seen such cases before in transplant patients and in patient undergoing remission induction for acute leukemia. The last five cases had, unfortunately, all undergon marrow ablative treatment before the first of this subgroup developed Aspergillus. Since all were housed on the unit, in this subgroup cross-contamination was a distinct possibility, despite measures taken to avoid such.

At this point, Rotstein and I closed the unit. Since we had failed to demonstrate a source of contamination (although we also suspected the heavy construction and the (retrospectively) inadequate air filtration system) Rotstein chose to begin a case control study. The tabulation of data had been essentially completed, and the conclusions reached, by the fall of 1983 . A "paper trail" does exist, demonstrating that the case control study was conceived of and in essence completed prior to the bringing of the suits. The long delay in its appearing in press was related to the usual: submissions, revisions, and re-submissions to different journals.
From a scientific standpoint, I doubt that anyone would question the fact that Aspergillus organisms were finding their way to the patients; their source was never proven. The tentative findings that patients with the underlying diagnosis of chronic myelocytic leukemia and patients who had been conditioned withr regimens containing standard dose cytosine arabinoside by infusion were more likely to develop Aspergillosis should not be dismissed lightly; there are possible therapeutic implications here.

I have not been associated with Roswell Park Memorial Institute since January 1984 and am no longer concerned with its numerous difficulties. However, I would hate to see anyone retain the suspicion that Rotstein would participate in any attempt to modify a scientific submission for nonscientific reasons. He is one of the most honest and careful investigators that I have met, and does not deserve even an implied slight on his character as a scientist or a physician.

Donald J. Higby, MD Chief, Hematology/Oncology Service Professor of Medicine Tufts University School of Medicine Boston, Massachusetts

\section{To the Editor:}

We were quite disturbed to read Dr. Rhame's editorial' ${ }^{\prime}$ about our article "An Outbreak of Invasive Aspergillosis Among Allogeneic Bone Marrow Transplants: A Case-Control Study," which appeared in the September 1985 issue of Infection Control. ${ }^{2}$ We found Rhame's commentary to be marred by inaccuracies and unsupported innuendos.

Rhame implies that we excluded facts in order to abbreviate our analysis. We feel this is unfounded and inappropriate. We included as many variables as possible in our analysis, as well as the environmental setting in which these events took place. It was not within the scope of our analysis to provide the reader with an historical perspective on the events which occurred surrounding the closure of the Bone Marrow Transplant Unit (BMTU) at Roswell Park Memorial Institute. The discrepancies which he claims exist between our account and that of the New York State Department of Health (NYSDH) ${ }^{3}$ report raise doubts regarding our honesty in reporting the data. On no occasion did we modify the facts; nor did we selectively report data in order to influence the impact of pending litigation. We would like to emphasize that our analysis was completed prior to the initiation of any litigation. Such litigation was launched against New York State, which operates Roswell Park Memorial Institute.

Rhame criticizes our article for its failure to consider the air filtration system as an explanation for the increased rate of aspergillosis observed among BMT recipients housed on the BMTU. If the air filtration system can truly be implicated as the major cause, resulting in the development of this outbreak among the BMT recipients in the BMTU, why then did transplant recipients 